\title{
Cell proliferation is induced in renal cell carcinoma through miR-92a-3p upregulation by targeting FBXW7
}

\author{
RONG ZENG ${ }^{1}$, JING HUANG $^{1}$, YUJIE SUN $^{1}$ and JUAN LUO ${ }^{2}$ \\ ${ }^{1}$ Teaching Experimental Center, School of Laboratory Medicine, Hubei University of Chinese Medicine, \\ Wuhan, Hubei 430065; ${ }^{2}$ Department of Internal Medicine, The Second Hospital of \\ Wuhan Iron and Steel (Group) Corporation, Wuhan, Hubei 430085, P.R. China
}

Received January 14, 2019; Accepted August 6, 2019

DOI: $10.3892 / \mathrm{ol} .2020 .11443$

\begin{abstract}
Renal cell carcinoma (RCC) is the most common type of kidney cancer whose incidence has gradually increased worldwide. MicroRNAs (miRNAs) represent a type of short endogenous non-coding RNA containing approximately 22 nucleotides, which are capable of regulating mRNAs at the post-transcriptional level in human cells. miRNAs have been demonstrated to mediate gene expression by influencing important regulatory genes. Accumulating evidence indicates that certain miRNAs are involved in RCC development. The present study investigated the underlying mechanism and functional role of miR-92a-3p in RCC cells using reverse transcription-quantitative polymerase chain reaction, western blotting, 3' UTR luciferase assay, cell proliferation assay and soft agar assay. The results demonstrated that miR-92a-3p expression level is significantly upregulated in RCC tissues and cell lines; however, F-box and WD repeat domain containing 7 (FBXW7) expression level was significantly downregulated in RCC tissues and cell lines. Subsequently, whether FBXW7 could be considered as a direct target of miR-92a-3p in RCC cells was investigated. The results demonstrated that miR-92a-3p overexpression significantly promoted RCC cell proliferation and colony formation. Conversely, miR-92a-3p downregulation significantly inhibited RCC cell proliferation and colony formation. In addition, FBXW7 knockdown significantly enhanced RCC cell proliferation and colony formation. Conversely, FBXW7 overexpression significantly inhibited RCC cell proliferation and colony formation. Collectively, these results demonstrated that
\end{abstract}

Correspondence to: Professor Juan Luo, Department of Internal Medicine, The Second Hospital of Wuhan Iron and Steel (Group) Corporation, 400 Qinghua Road, Wuhan, Hubei 430085, P.R. China E-mail: juan.luo.md@gmail.com

Key words: microRNA-92a-3p, F-box and WD repeat domain containing 7, cell proliferation, anchorage-independent growth
miR-92a-3p/FBXW7 pathway may represent a novel strategy and therapeutic target for RCC.

\section{Introduction}

Renal cell carcinoma (RCC) is the most common type of kidney cancer (1). The incidence of RCC has gradually increased worldwide in the last decades (2). In 2015, 12,547 new cases of RCC were registered in the UK, with an Age-Standardized Incidence Rate of 20.8 (2). As RCC has acquired chemoresistance, its prognosis remains low $(3,4)$. In addition, only $10 \%$ of patients with RCC and metastases survive longer than five years $(5,6)$. Furthermore, the underlying mechanisms of RCC progression are poorly understood. A previous study reported that molecular-targeted therapies have significant therapeutic efficacy in RCC (7). It is therefore crucial to identify novel diagnostic biomarkers in order to allow the development of potential therapeutic interventions in RCC.

MicroRNAs (miRNAs) are small non-coding RNAs ( $\sim 22$ nucleotides in length) that regulate gene expression on a post-transcriptional level through base-pairing with complementary sequences of the 3'untranslated region (UTR) of mRNAs (8). Recent studies demonstrated that miR-720 and eight other miRNAs serve crucial roles in $\operatorname{RCC}(9,10)$. For example, miR-92a-3p has been reported to serve a crucial role in the progression of various types of cancer, including lung cancer, esophageal squamous cell carcinoma, colorectal, breast, ovarian, and cervical cancer (11-16). However, the functional significance and molecular mechanism of miR-92a-3p in $\mathrm{RCC}$ remain unclear.

F-box and WD repeat domain containing 7 (FBXW7) has been reported to act as a general tumor suppressor and to be one of the most frequently dysregulated ubiquitin-proteasome system proteins in human cancer (17). It has been reported that FBXW7 is a substrate specifying subunit of the evolutionarily conserved SKP1-CUL1-F-box ubiquitin ligase complex, and that FBXW7 functions as a cell cycle regulatory gene which protein products that regulate the stability of numerous oncoprotein substrates, including cyclin E, c-Myc, Notch, c-Jun, mammalian target of rapamycin and MCL1 $(18,19)$. The dysregulation of FBXW7 expression therefore serves critical roles in cancer development. Furthermore, FBXW7 was demonstrated to be a functional target of numerous miRNAs 
involved in the regulation of cancer progression $(20,21)$. However, the significance of miRNAs and FBXW7 association in RCC requires further investigation

The present study investigated the effects of miR-92a-3p in RCC cells. In addition, the association between miR-92a-3p and its direct target gene FBXW7 was determined in order to highlight the underlying mechanisms of miR-92a-3p in the progression of RCC.

\section{Materials and methods}

Cell culture and tumor tissues. The human proximal tubule epithelial (HK-2) and human renal cancer (ACHN and SN12PM6) cell lines were purchased from the American Type Culture Collection. Cells were cultured in Dulbecco's Modified Eagle's medium (Thermo Fisher Scientific, Inc) supplemented with $10 \%$ (v/v) fetal bovine serum (Thermo Fisher Scientific, Inc.) and placed at $37^{\circ} \mathrm{C}$ in a humidified incubator containing $5 \% \mathrm{CO}_{2}$.

A total of 16 pairs of RCC tissues and adjacent non-tumor tissues were obtained from the tissue bank of the Hubei University of Chinese Medicine. The inclusion criteria were as follows: i) Provision of prior nephrectomy; ii) histological confirmation of clear-cell RCC with metastases; iii) Eastern Cooperative Oncology Group performance status of 0 or 1; and iv) adequate hematologic, hepatic, renal and cardiac functions. Patients were excluded if they had cardiac disease, antibiotic-requiring systemic infections, coagulation disorders, second malignancies, organ allografts, corticosteroid dependence, and infection with human immunodeficiency virus or hepatitis. The age of patients ranged from 51 to 82 years (median age 67 years) and $68 \%$ of patients were men. The mean tumor size was $4.7 \mathrm{~cm}$ and histologic necrosis was present in $25.1 \%$ of cases. Tissues were collected between January 2015 and November 2017, immediately minced on ice, frozen in liquid nitrogen and stored at $-80^{\circ} \mathrm{C}$ until further analysis. Patients were staged using radiographic reports and postoperative pathological data according to the 2010 American Joint Committee on Cancer Tumor-Node-Metastasis classification (22). Patients with N1- or M1-stage tumors were considered to have metastatic disease and were excluded from this study. The present study was approved by the Ethics Committee of Hubei University of Chinese Medicine, and informed consent was obtained from each patient.

Reverse transcription-quantitative polymerase chain reaction $(R T-q P C R)$. A mirVana ${ }^{\mathrm{TM}}$ miRNA Isolation Kit (Ambion; Thermo Fisher Scientific, Inc.) was used to extract total RNA from tissue samples and cells according to the manufacturer's instructions. Subsequently, RNAs were reverse transcribed into cDNA using a High Capacity RNA-to-cDNA Kit (Thermo Fisher Scientific, Inc.) following removal of residual DNA by DNase I (Invitrogen; Thermo Fisher Scientific, Inc.). FBXW7 gene expression was detected by TaqMan $^{\mathrm{TM}}$ RT-qPCR in a QuantStudio 6 Flex System (Thermo Fisher Scientific, Inc.). $\beta$-actin was used as an internal control. The relative expression level of FBXW7 was presented as the fold difference relative to $\beta$-actin. The relative expression level of FBXW7 was normalized to endogenous controls and was expressed as $2^{-\Delta \Delta \mathrm{Cq}}(23)$.
To quantify the expression of mature miRNAs, total RNA was reverse-transcribed using a TaqMan ${ }^{\mathrm{TM}}$ Advanced miRNA cDNA Synthesis Kit, according to the manufacturer's recommended protocols (Applied Biosystems; Thermo Fisher Scientific, Inc.). U6 small nuclear RNA (snRNA) was used as the internal control and reverse-transcribed using a TaqMan $^{\mathrm{TM}}$ microRNA Reverse Transcription Kit, according to the manufacturer's protocol. The relative expression level of miR-92a-3p was calculated as the fold difference relative to U6. All TaqMan probes were purchased from Thermo Fisher Scientific, Inc. (FBXW7, cat. no. Hs00217794; $\beta$-actin, cat. no. Hs99999903; miR-92a-3p, cat no. 477827; U6, cat no. 001973). The thermocycling conditions were as follows: Hold stage, $95^{\circ} \mathrm{C}$ for $20 \mathrm{sec}$; PCR stage, $95^{\circ} \mathrm{C}$ for $1 \mathrm{sec}, 60^{\circ} \mathrm{C}$ for $20 \mathrm{sec}$ for 1 cycle, 40 cycles total.

Western blotting. Tissues and ACHN and SN12PM6 cell lines were lysed in ice cold RIPA Lysis and Extraction buffer (Thermo Fisher Scientific, Inc.). Briefly, 0.5 or $1 \mathrm{ml}$ RIPA buffer was added to $5 \times 10^{6}$ cells in suspension or $0.1 \mathrm{~g}$ tissue, respectively. Protein concentration was determined using a DC Protein Assay kit (Bio-Rad Laboratories, Inc.). Proteins (15 $\mu \mathrm{g})$ were separated on 4-15\% precast gels (Bio-Rad Laboratories, Inc.) and transferred onto nitrocellulose membranes (Bio-Rad Laboratories, Inc.). Membranes were blocked with 5\% skimmed milk in TBST for $1 \mathrm{~h}$ at room temperature, and incubated with primary antibodies against FBXW7 (1:1,000; cat. no. ab109617; Abcam), CDC42 (1:1,000; cat. no. ab187643; Abcam) and $\beta$-actin (1:500; cat. no. sc-47778; Santa Cruz Biotechnology, Inc.) at $4^{\circ} \mathrm{C}$ overnight. Membranes were washed three times with TBST and incubated with the goat anti-rabbit horseradish peroxidase (HRP)-conjugated secondary antibody (1:2,000; cat. no. STAR124P; Bio-Rad Laboratories, Inc.) or goat anti-mouse HRP-conjugated secondary antibody (1:5,000; cat. no. STAR207P; Bio-Rad Laboratories, Inc.) for $2 \mathrm{~h}$ at room temperature. Bands were detected using the Enhanced Chemiluminescence Kit (Pierce; Thermo Fisher Scientific, Inc.). Each experiment was repeated three times. In order to avoid possible problems related to incomplete stripping, all results were taken from separate blots. The relative protein expression was normalized to endogenous control $\beta$-actin using ImageJ software version 1.50i (National Institutes of Health).

Cell transfection. The miR-92a-3p lentivirus expression vector and inhibitor hsa-miR-92b-3p lentivector (anti-miR-92a-3p) were purchased from Applied Biological Materials Inc. and were used to stably overexpress or knock down miR-92a-3p, respectively, in ACHN and SN12PM6 cell lines. Non-relevant sequence inserts acted as negative controls for miR-92a-3p and miR-92a-3p inhibitor, named miR-control and anti-miR-control, respectively (Applied Biological Materials Inc.). The lentiviral construct expressing human FBXW7 short hairpin RNA (sh-FBXW7) that was used to knock down FBXW7 and the negative control (sh-control) were generated using pLVTHM-GFP lentiviral RNAi expression system (Addgene, Inc.) as previously described (24). Furthermore, the lentivirus-covered coding region FBXW7 cDNA sequence (FBXW7-OE) was used to overexpress FBXW7, whereas control-OE was used as negative control lentivirus (both from 
A

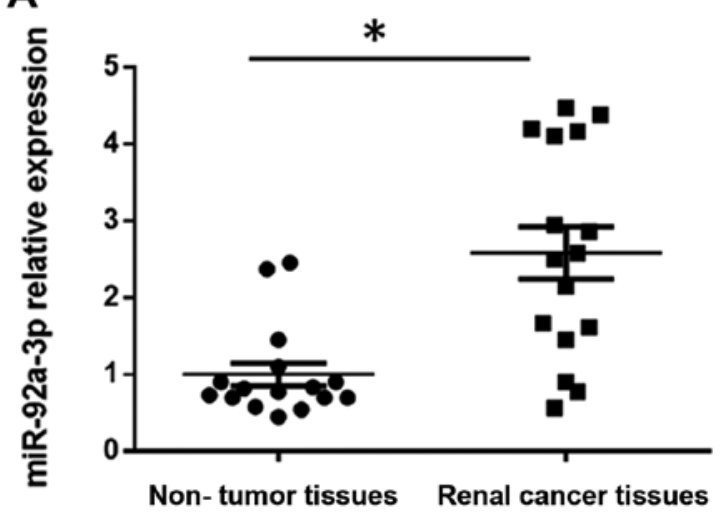

B

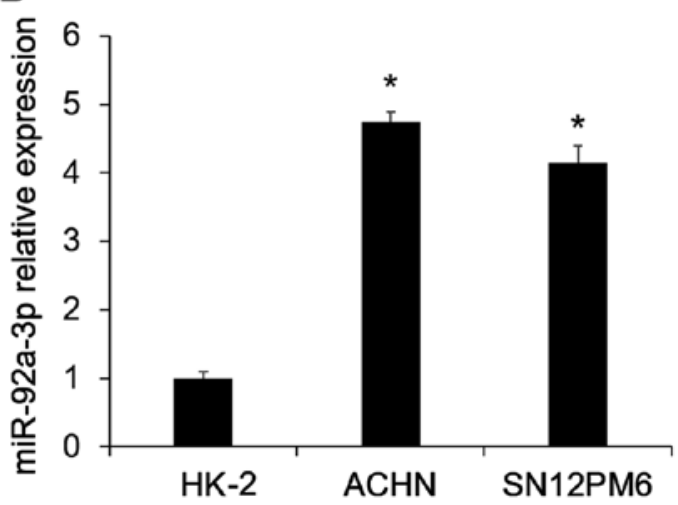

Figure 1. miR-92a-3p expression in RCC tissues and cell lines. (A) The mean level of miR-92a-3p expression in RCC tissues was significantly elevated compared with matched non-tumor tissues, as determined by RT-qPCR. * $\mathrm{P}<0.05$ vs. non-tumor tissues ( $\mathrm{n}=16$ ). (B) RT-qPCR was used to compare the differences in miR-92a-3p expression level between the non-tumorigenic renal cell line HK-2 and RCC cell lines ACHN and SN12PM6. * $\mathrm{P}<0.05$ vs. HK-2 ( $=3$ ). $\mathrm{RCC}$, renal cell carcinoma; RT-qPCR, reverse transcription-quantitative polymerase chain reaction.

GeneChem, Inc.). ACHN and SN12PM6 cells (6x105 cells) were infected with $2.5 \mu \mathrm{g}$ of lentiviral particles containing the aforementioned vectors. Media containing $2 \mu \mathrm{g} / \mathrm{ml}$ puromycin (Sigma-Aldrich; Merck KGaA) was used to select infected cells after $48 \mathrm{~h}$. The successfully infected cells were maintained in complete medium containing $0.5 \mu \mathrm{g} / \mathrm{ml}$ puromycin.

All transfection procedures were performed using $5 \mu \mathrm{g} / \mathrm{ml}$ polybrene (GeneChem, Inc.) according to the manufacturer's instructions. Cells were collected for subsequent measurements after $48 \mathrm{~h}$ transfection.

Target gene analysis of miR-92a-3p. The available databases of TargetScan (http://www.targetscan.org/) and miRanda (http://www.microrna.org/ and http://www.mirbase.org/) were used to search for candidate targets of miR-92a-3p. The term 'miR-92a-3p' was typed in the search box and the candidate genes were then provided.

3' UTR dual luciferase assay. For reporter assays, the 3'-UTR of FBXW7 within the predicted target sites was cloned into the pRL-TK vector (Promega Corporation) for luciferase expression, as previously described $(25,26)$. Cells were seeded into 96-well plates at a density of $2 \times 10^{4}$ cells/well. Cells were co-transfected with $120 \mathrm{ng}$ miR-92a-3p or miR-control and $30 \mathrm{ng}$ of the wild-type 3'-UTR of FBXW7 mRNA. Following $48 \mathrm{~h}$ transfection, the cells were collected and gene expression was assessed using the dual luciferase assay system (Promega Corporation), according to the manufacturer's instructions. The pRL-TK expressing Renilla luciferase was co-transfected as an internal control to reduce variation from different transfection and harvest efficiencies (27).

Cell proliferation assay. ACHN and SN12PM6 cells that were transfected with different vectors were seeded into 96-well plates at a density of $5 \times 10^{3}$ cells/well and incubated for $48 \mathrm{~h}$. The Cell Counting Kit-8 (CCK-8) assay (Invitrogen; Thermo Fisher Scientific, Inc.) was used to measure cell proliferation, according to the manufacturer's protocol. Cell proliferation was detected at $0,24,48,72,96$ and $120 \mathrm{~h}$. Briefly, $10 \mu \mathrm{l}$ CCK-8 solution was added to each well and incubated for $2 \mathrm{~h}$ at $37^{\circ} \mathrm{C}$. Optical density was measured at $450 \mathrm{~nm}$ with an automatic microplate reader (28) and data were expressed as the means \pm standard error $(\mathrm{SE})$.

Soft agar assay. Anchorage-independent growth is the ability of transformed cells to grow independently on a solid surface and is considered as a hallmark of carcinogenesis (29). The anchorage-independent growth of ACHN and SN12PM6 cells that were transfected with different vectors was examined by colony formation in soft agarose. Some 6-well plates were coated with $0.5 \%(\mathrm{v} / \mathrm{v})$ agarose diluted in cell media at $42^{\circ} \mathrm{C}$ for $1 \mathrm{~h}$. Cells $(5,000 /$ well) were resuspended in heated medium containing $0.4 \%(\mathrm{v} / \mathrm{v})$ low-melt agarose and incubated in the 6-well plate for 1-4 weeks. Colonies were stained with crystal violet $(0.5 \% \mathrm{v} / \mathrm{v}$; EMD Millipore) for $15 \mathrm{~min}$ at room temperature and counted manually by light microscopy.

Statistical analysis. Each experiment was set up in triplicate and repeated three times. A two-tailed unpaired Student's t-test was used to assess significance between two conditions. One-way ANOVA followed by Tukey's post-hoc test was used to compare significant differences between more than two conditions. Means and SEs were calculated from numerical data. The SPSS software package (version 20.0; IBM Corp.) was used to perform statistical analyses. $\mathrm{P}<0.05$ was considered to indicate a statistically significant difference.

\section{Results}

miR-92a-3p is upregulated in RCC tissues and cells. According to preliminary miRNA microarray data for differentially expressed miRNAs in RCC tissues and adjacent non-tumor tissues, miR-92a-3p is one of the upregulated miRNAs in RCC tissues (data not shown). To verify these preliminary results, 16 pairs of RCC tissues and matched adjacent non-tumor tissues were tested for miR-92a-3p expression level. The results demonstrated that the mean level of miR-92a-3p expression was significantly upregulated by 2.6 -fold $(\mathrm{P}<0.05)$ in RCC tissues compared with matched adjacent non-tumor tissues (Fig. 1A). Subsequently, miR-92a-3p expression level was determined by RT-qPCR in the RCC cell lines ACHN and SN12PM6 and the non-tumorigenic renal cell line HK-2. The 
A

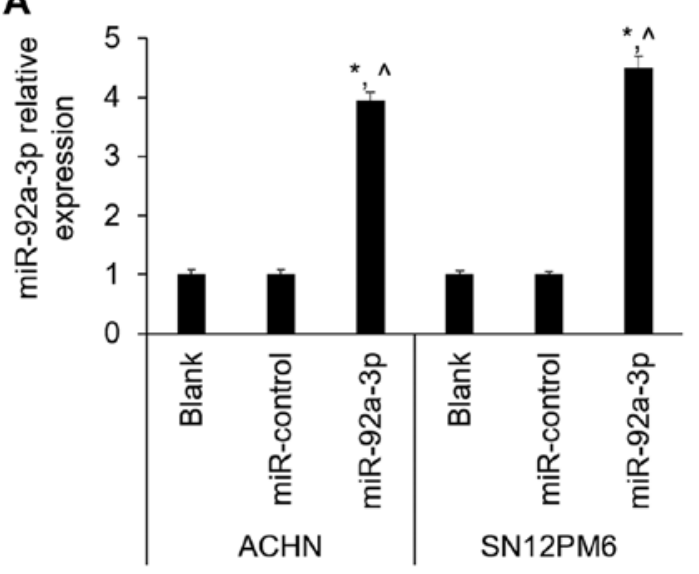

C

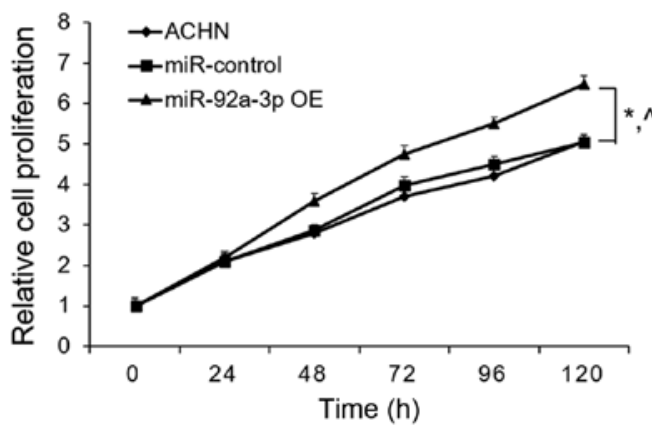

D
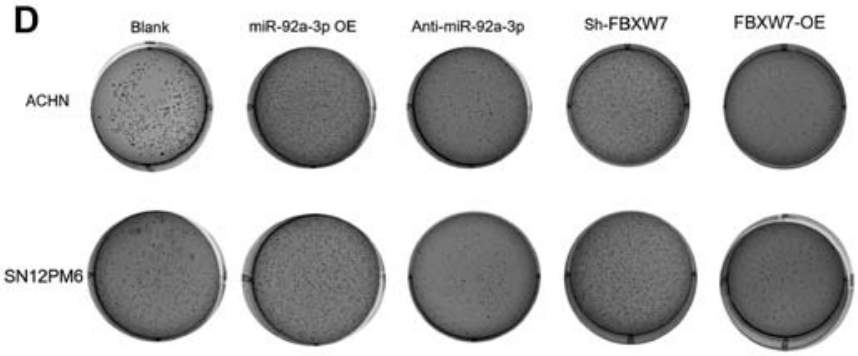

$\mathbf{F}$

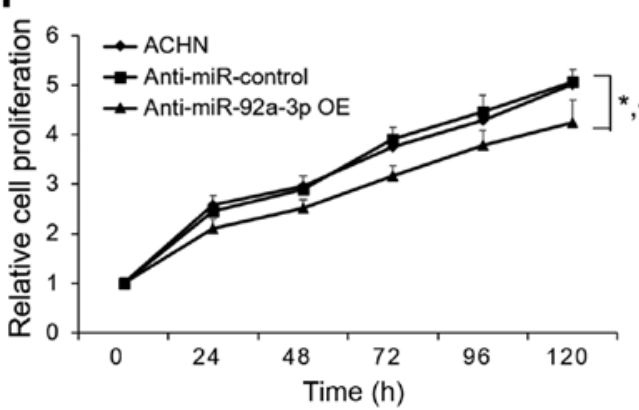

B

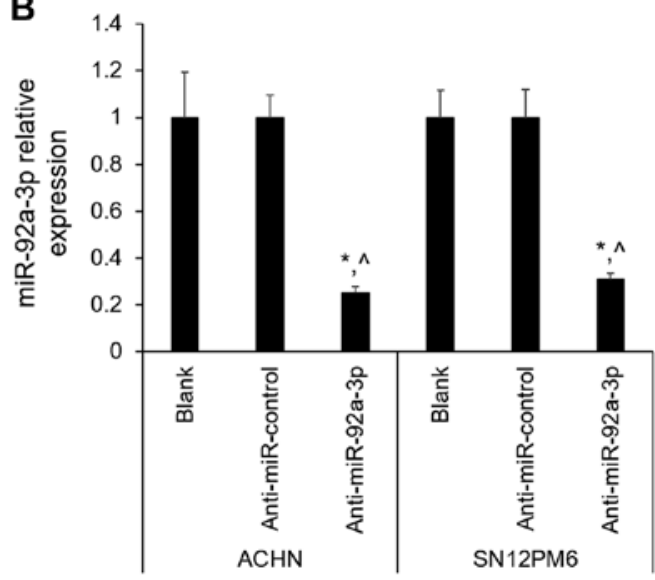

E
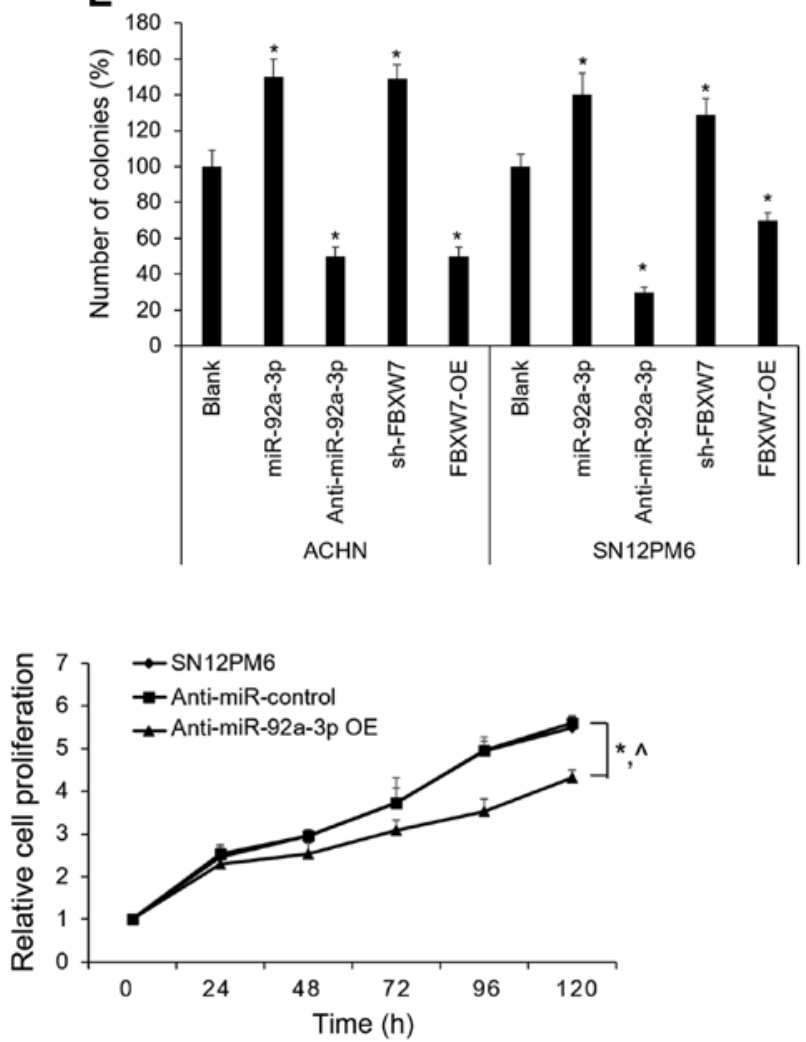

Figure 2. Biological effect of miR-92a-3p overexpression on ACHN and SN12PM6 cells. (A) RCC cell lines ACHN and SN12PM6 stably overexpressed miR-92a-3p following miR-92a-3p transfection. " $\mathrm{P}<0.05$ vs. untransfected cells (blank); ${ }^{\wedge} \mathrm{P}<0.05$ vs. miR-control $(\mathrm{n}=3)$. (B) miR-92a-3p was stably downregulated in $R C C$ cell lines ACHN and SN12PM6 following anti-miR-92a-3p transfection. " $\mathrm{P}<0.05$ vs. untransfected cells (blank); ${ }^{\wedge} \mathrm{P}<0.05$ vs. anti-miR-control (n=3). (C) miR-92a-3p overexpression stimulated ACHN and SN12PM6 cell proliferation. " $\mathrm{P}<0.05$ vs. untransfected cells; ${ }^{\wedge} \mathrm{P}<0.05$ vs. miR-control ( $\mathrm{n}=3$ ). (D) Colony formation assay demonstrated that miR-92a-3p-overexpression and FBXW7-knockdown accelerated colony formation of ACHN and SN12PM6 cells. Conversely, miR-92a-3p knockdown and FBXW7 overexpression inhibited colony formation of ACHN and SN12PM6 cells. (E) Number of colony forming cells/well expressed as percentage of untransfected cells (blank) and presented as the mean \pm standard error. "P $<0.05$ vs. blank. (F) miR-92a-3p knockdown inhibited ACHN and SN12PM6 cell proliferation. ${ }^{*} \mathrm{P}<0.05$ vs. untransfected cells, $\wedge \mathrm{P}<0.05$ vs. anti-miR-control $(\mathrm{n}=3)$. FBXW7, F-box and WD repeat domain containing 7 ; RCC, renal cell carcinoma. 

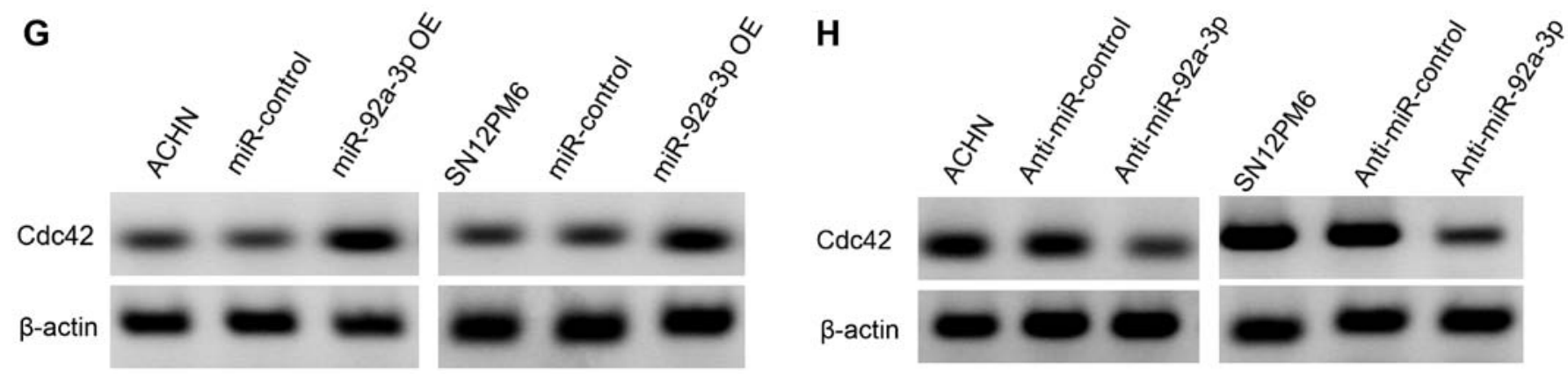

Figure 2. Continued. (G and H) Western blotting determination of Cdc42 protein expression level in ACHN and SN12PM6 cells following miR-92a-3p or anti-miR-92a-3p transfection. FBXW7, F-box and WD repeat domain containing 7; RCC, renal cell carcinoma.

results demonstrated that miR-92a-3p relative expression level was significantly upregulated in ACHN and SN12PM6 cells compared with HK-2 cells (Fig. 1B).

Effects of miR-92a-3p on RCC cell proliferation. To determine the biological function of miR-92a-3p, the miR-92a-3p and anti-miR-92a-3p were stably expressed in ACHN and SN12PM6 cell lines, and the endogenous expression level of miR-92a-3p in ACHN and SN12PM6 cells was determined by RT-qPCR. The results demonstrated that miR-92a-3p expression level was significantly increased in miR-92a-3p-overexpressing cells compared with miR-control and untransfected cells (blank) (Fig. 2A). Conversely, miR-92a-3p expression level was significantly decreased following anti-miR-92a-3p cell transfection compared with anti-miR-control and untransfected cells (blank) (Fig. 2B). Furthermore, miR-92a-3p-overexpressing cells exhibited significant increased cell proliferation compared with miR-control and untransfected cells (Fig. 2C). In addition, the number of colonies formed under anchorage-independent conditions was significantly increased $(\mathrm{P}<0.05)$ in miR-92a-3p-overexpressing cells compared with untransfected ACHN and SN12PM6 cells (Fig. 2D and E). Conversely, miR-92a-3p downregulation inhibited cell proliferation compared with anti-miR-control and untransfected cells (Fig. 2F). In particular, the number of colonies formed under anchorage-independent conditions was also decreased $(\mathrm{P}<0.05)$ following miR-92a-3p knockdown (Fig. 2D and E) compared with untransfected ACHN and SN12PM6 cells. In addition, the protein expression of the cell proliferation-associated marker $\mathrm{Cdc} 42$, was increased in cells overexpressing miR-92a-3p compared with miR-control and untransfected cells (Fig. 2G); however, Cdc42 protein expression was decreased in cells following miR-92a-3p knockdown compared with anti-miR-control and untransfected cells (Fig. 2H).

FBXW7 is downregulated in RCC tissues and cells. FBXW7 expression level was determined in 16 RCC tissue samples by RT-qPCR and western blotting. The results demonstrated that FBXW7 mRNA expression levels was significantly lower in RCC tissues compared with in matched adjacent non-tumor tissues $(\mathrm{P}<0.05$; Fig. $3 \mathrm{~A})$. Furthermore, FBXW7 protein expression was also lower in the RCC tissues compared with paired non-tumor tissues (Fig. 3B). Subsequently, FBXW7 mRNA and protein levels were determined in HK-2, ACHN and SN12PM6 cells by
RT-qPCR and western blotting. The results demonstrated that FBXW7 mRNA and protein expression levels were significantly downregulated in ACHN and SN12PM6 cells compared with HK-2 cells (Fig. 3C-E).

$F B X W 7$ is the direct target of miR-92a-3p. The complimentary sequence of miR-92a-3p has already been verified in the 3'UTR of FBXW7 mRNA in human hepatocellular carcinoma (26). In the present study, the results from the 3'-UTR luciferase assay confirmed that FBXW7 was the direct target of miR-92a-3p in ACHN and SN12PM6 cells. Furthermore, miR-92a-3p significantly suppressed the luciferase activity of FBXW7, which was not the case with miR-control (Fig. 4A). In addition, FBXW7 mRNA and protein expression were significantly decreased following miR-92a-3p overexpression in ACHN and SN12PM6 cells (Fig. 4B-D). Conversely, FBXW7 mRNA and protein expression were significantly increased following miR-92a-3p knockdown (Fig. 4E-G). These results indicated that FBXW7 was directly suppressed by miR-92a-3p in RCC cells.

Alterations in FBXW7 expression mimic the effects of miR-92a-3p on RCC cells. To further confirm that FBXW7 may be a downstream functional target of miR-92a-3p, FBXW7 was knocked down or overexpressed by FBXW7 shRNA or FBXW-OE lentivirus, respectively, in ACHN and SN12PM6 cell lines. The efficiency of FBXW7 knockdown or overexpression was verified by RT-qPCR and western blotting. As presented in Fig. 5A and B, FBXW7 shRNA significantly reduced the mRNA expression level of FBXW7 compared with untransfected cells and sh-control, whereas FBXW-OE significantly upregulated FBXW7 mRNA expression compared with untransfected cells and control-OE. To further confirm these results, western blotting was used to determine FBXW7 protein level following sh-FBXW7 or FBXW7-OE-transfection of ACHN and SN12PM6 cells. The results demonstrated that FBXW7 protein level was significantly decreased after sh-FBXW7 transfection compared with sh-control and untransfected cells (Fig. 5C and D). Conversely, FBXW7 protein level was significantly upregulated following FBXW7 overexpression compared with control-OE and untransfected cells (Fig. 5E and F). In addition, FBXW7 knockdown significantly stimulated cell proliferation (Fig. 5G) and increased the number of colonies formed under anchorage-independent conditions compared with 


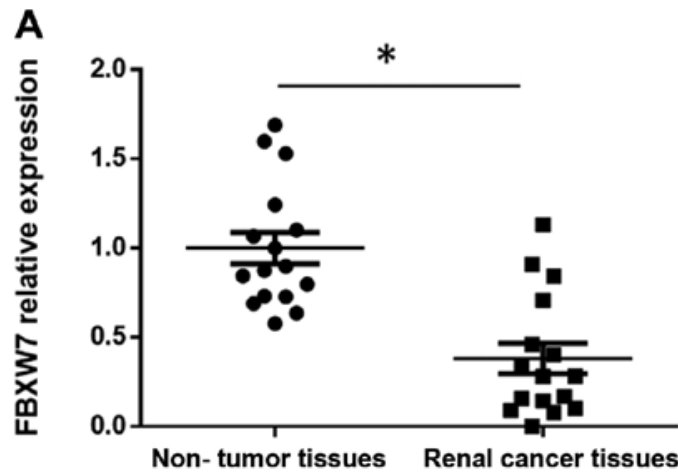

\section{B}

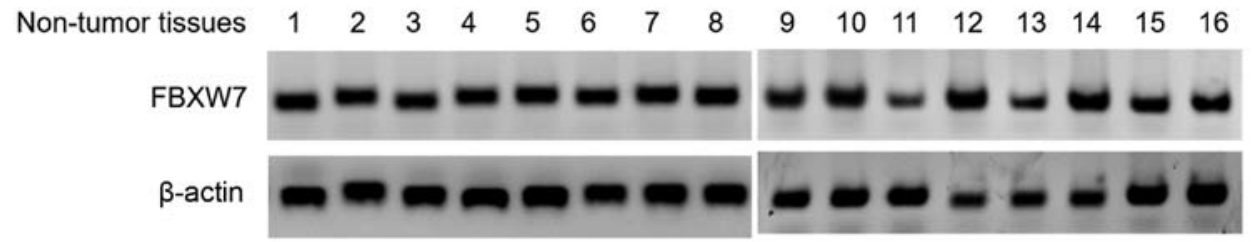

$\begin{array}{lllllllllllllllll}\text { Renal cancer tissues } & 1 & 2 & 3 & 4 & 5 & 6 & 7 & 8 & 9 & 10 & 11 & 12 & 13 & 14 & 15 & 16\end{array}$
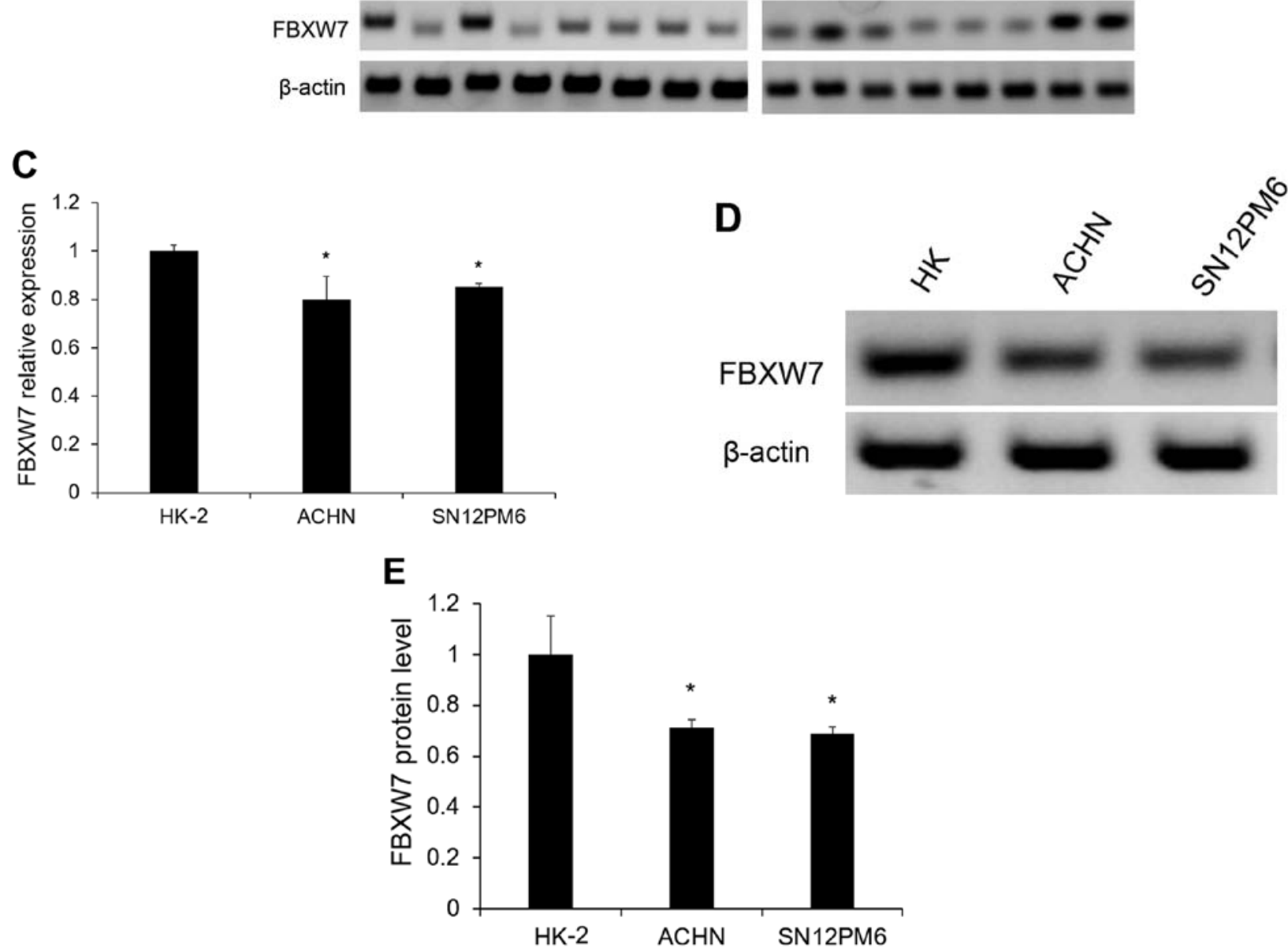

Figure 3. FBXW7 downregulation in RCC tissues and cell lines. (A) RT-qPCR demonstrated that FBXW7 expression level was significantly downregulated in RCC tissues compared with matched non-tumor tissues. " $\mathrm{P}<0.05$ vs. non-tumor tissues (n=16). (B) FBXW7 protein expression was determined in RCC tissues and paired non-tumor tissues by western blotting. (C) RT-qPCR was used to compare differences in the expression of FBXW7 between the non-tumorigenic renal cell line HK-2 and RCC cell lines ACHN and SN12PM6. "P<0.05 vs. HK-2 (n=3). (D) FBXW7 protein expression was determined in HK-2, ACHN and SN12PM6 cell lines by western blotting. (E) Western blotting bands were quantified using ImageJ software. Relative FBXW7 expression levels were normalized to $\beta$-actin. ${ }^{*} \mathrm{P}<0.05$ vs. HK-2 (n=3). FBXW7, F-box and WD repeat domain containing 7; RCC, renal cell carcinoma; RT-qPCR, reverse transcription-quantitative polymerase chain reaction.

untransfected cells (Fig. 2D), which was similar to the results observed following miR-92a-3p overexpression. Conversely,
FBXW7 overexpression significantly inhibited cell proliferation (Fig. $5 \mathrm{H}$ ) and decreased the number of colonies formed 
A

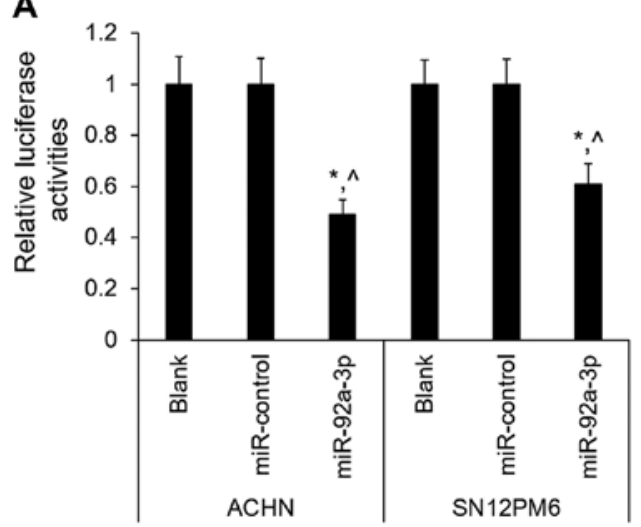

B

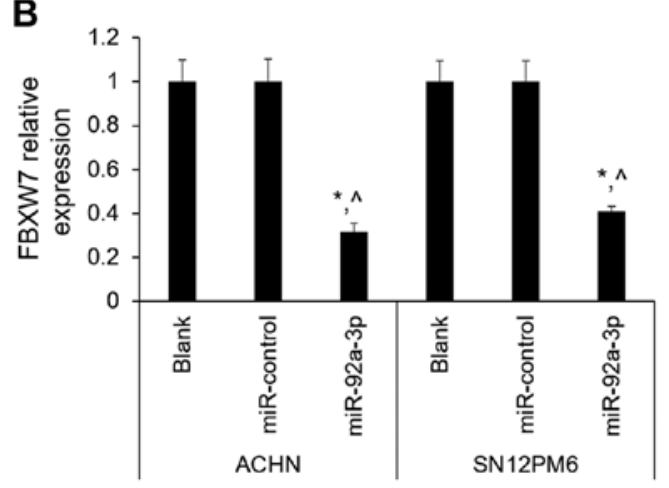

D

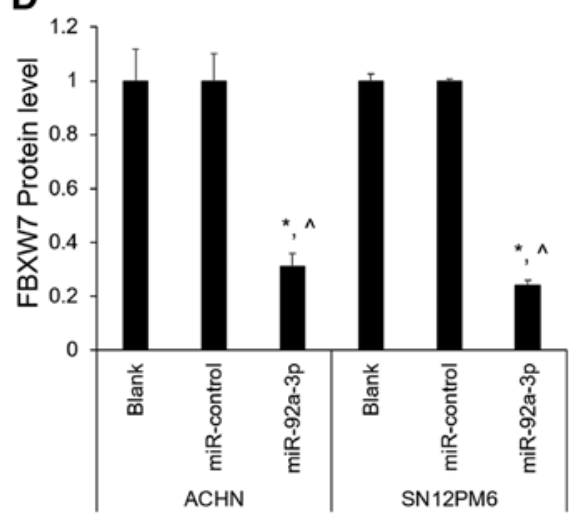

E

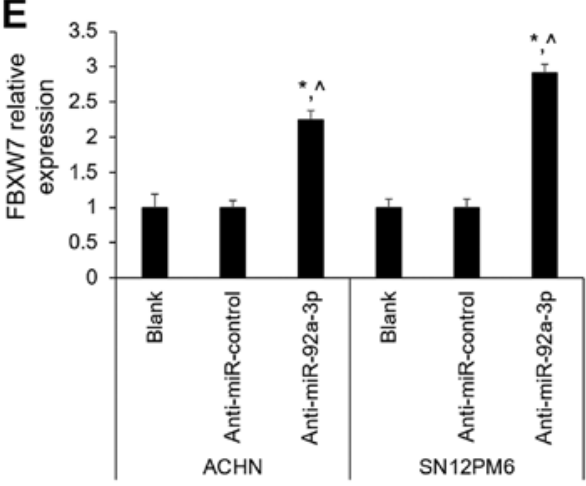

C

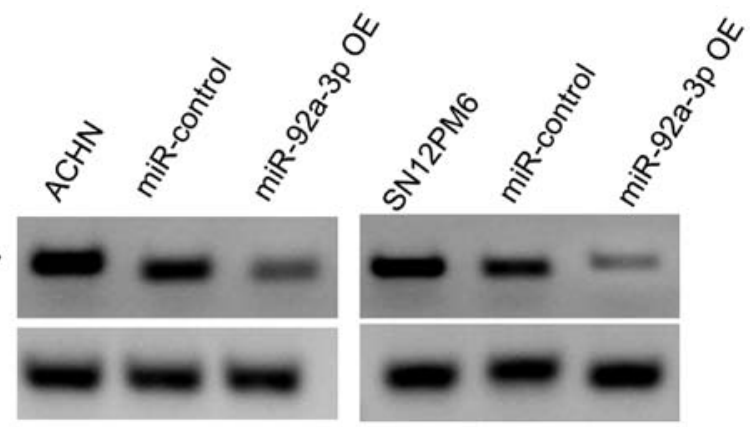

$\mathbf{F}$
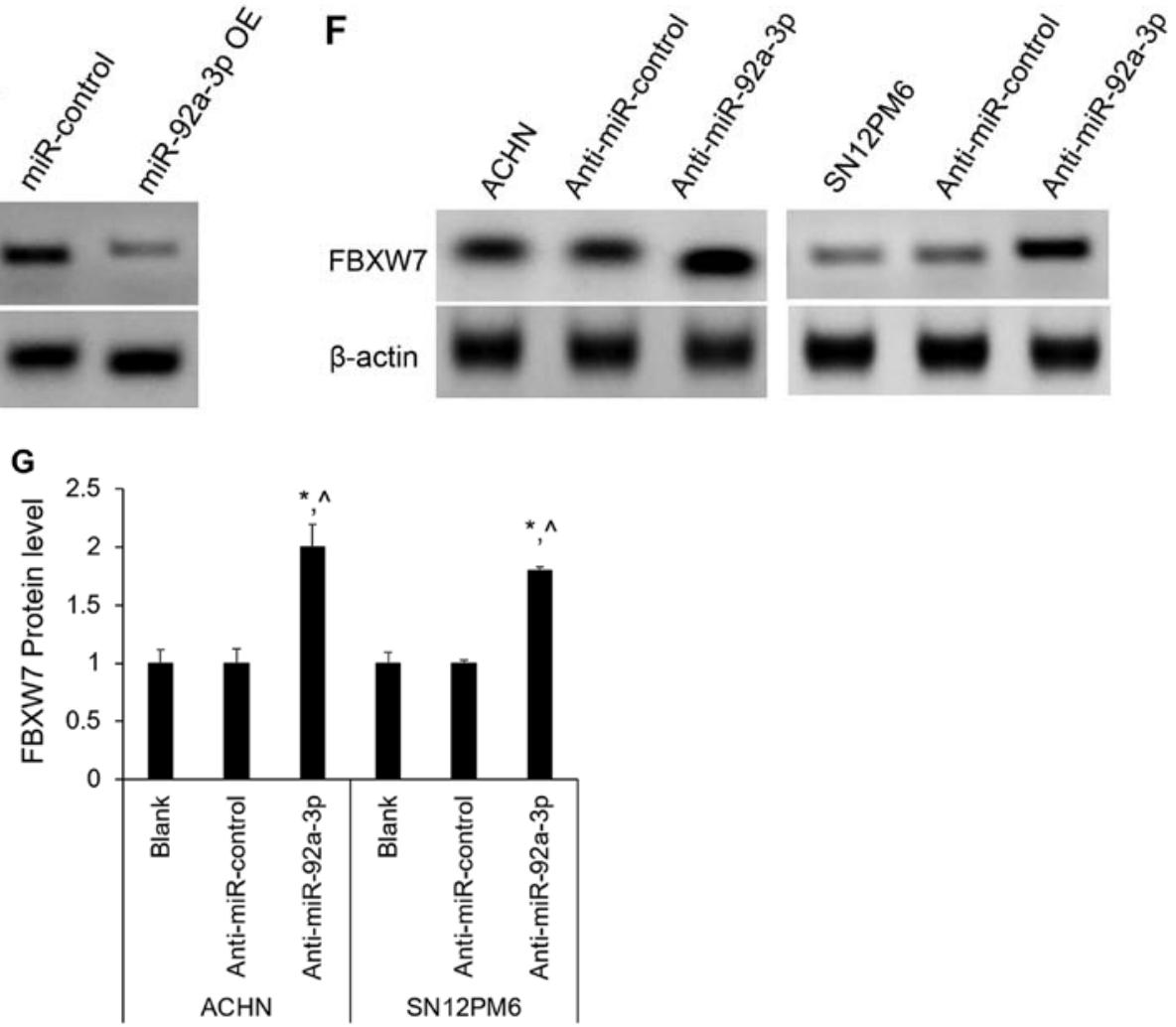

Figure 4. FBWX7 was directly suppressed by miR-92a-3p. (A) 3'-UTR luciferase reporter assay was used to confirm that miR-92a-3p bound to specific regions in the FBXW7 3'-UTR region. " $\mathrm{P}<0.05$ vs. blank; ${ }^{\wedge} \mathrm{P}<0.05$ vs. miR-control $(\mathrm{n}=3$ ). (B) FBXW7 mRNA level was assessed following miR-92a-3p overexpression by RT-qPCR. "P $<0.05$ vs. blank; ${ }^{\wedge} \mathrm{P}<0.05$ vs. miR-control $(\mathrm{n}=3)$. (C) Western blotting of FBXW7 in ACHN and SN12PM6 cells not transfected with lentivirus (blank) or transfected with lentivirus expressing miR-92a-3p or miR-control. (D) Western blotting bands were quantified using ImageJ software. Relative FBXW7 expression levels were normalized to $\beta$-actin. " $\mathrm{P}<0.05$ vs. blank; ${ }^{\wedge} \mathrm{P}<0.05$ vs. miR-control (n=3). (E) FBXW7 mRNA level was measured following anti-miR-92a-3p overexpression in ACHN and SN12PM6 cell lines by RT-qPCR. ${ }^{*} \mathrm{P}<0.05$ vs. blank; ${ }^{\wedge} \mathrm{P}<0.05$ vs. anti-miR-control (n=3). (F) FBXW7 protein expression was determined by western blotting in ACHN and SN12PM6 cell lines not transfected with lentivirus (blank) or transfected with a lentivirus expressing anti-miR-92a-3p or anti-miR-control. (G) Western blotting bands were quantified using ImageJ software. Relative FBXW7 expression levels were normalized to $\beta$-actin. ${ }^{*} \mathrm{P}<0.05$ vs. blank, ${ }^{\wedge} \mathrm{P}<0.05$ vs. anti-miR-control ( $\mathrm{n}=3$ ). FBXW7, F-box and WD repeat domain containing 7; RT-qPCR, reverse transcription-quantitative polymerase chain reaction. 
A

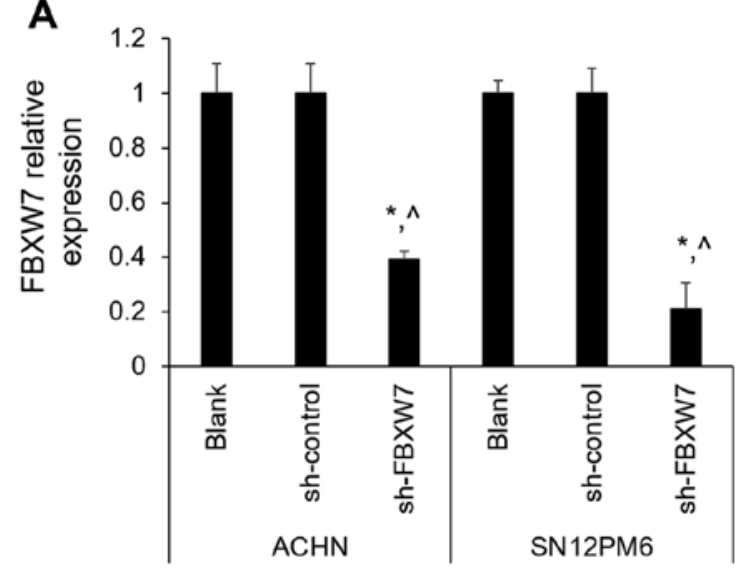

B

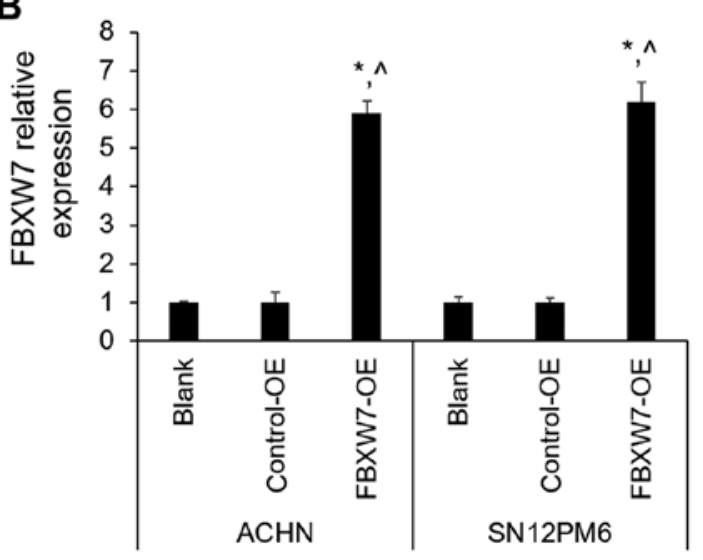

C

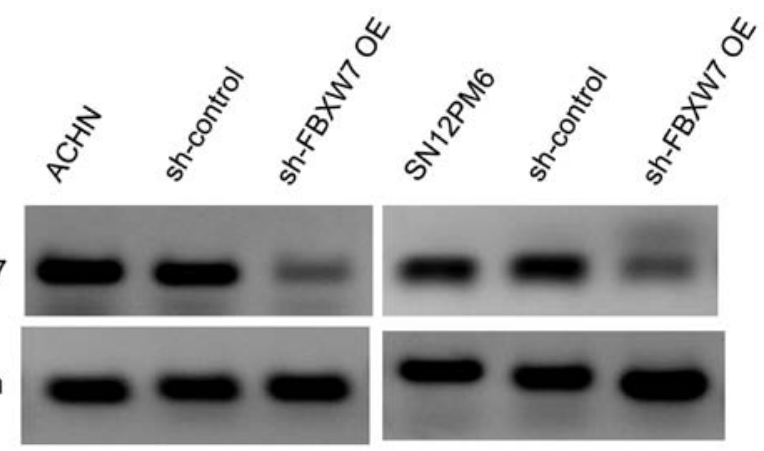

$\mathbf{G}$

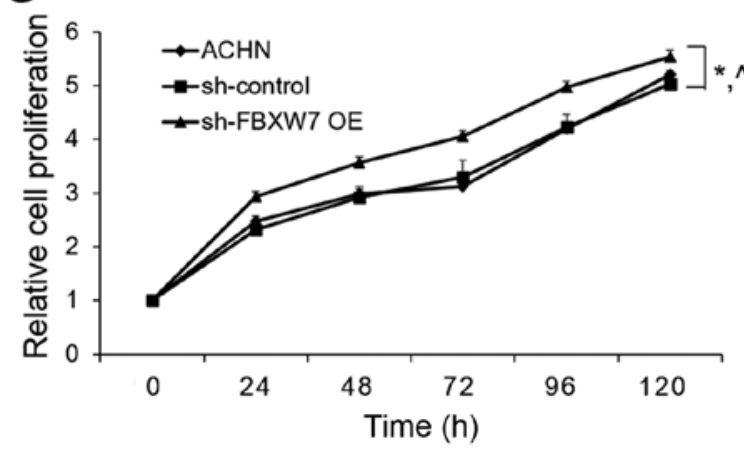

D
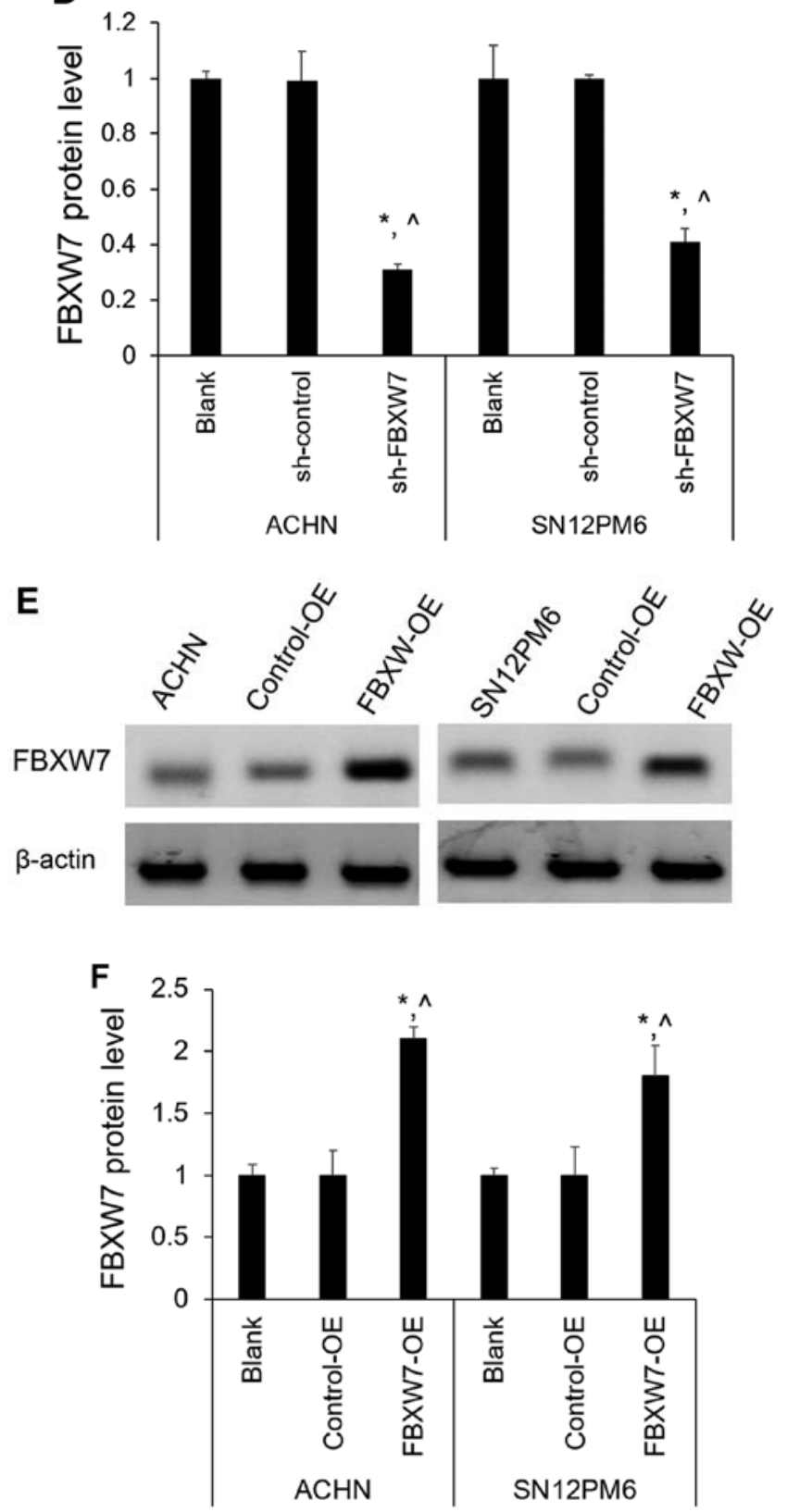

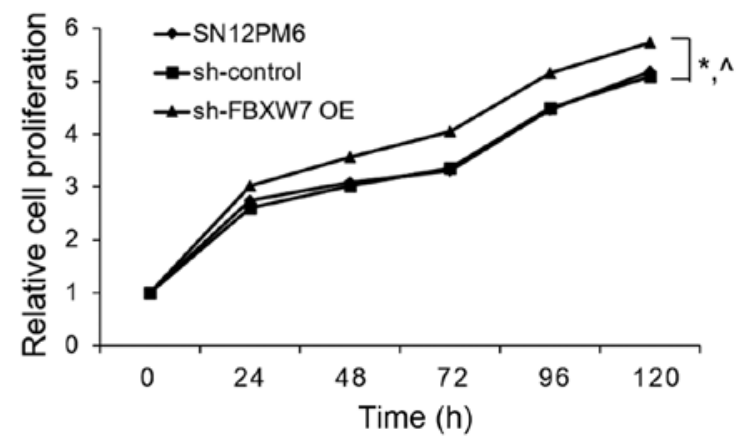

Figure 5. Biological effects of FBXW7 alteration in ACHN and SN12PM6 cell lines. (A) FBXW7 mRNA expression level was determined by RT-qPCR following sh-FBXW7 transfection (n=3). (B) FBXW7 mRNA expression level was determined by RT-qPCR following FBXW7 overexpression (n=3). (C) FBXW7 protein expression was determined by western blotting following sh-FBXW7 transfection. (D) Western blotting bands were quantified using ImageJ software. Relative FBXW7 expression levels were normalized to $\beta$-actin. " $\mathrm{P}<0.05$ vs. untransfected cells (Blank); ${ }^{\wedge} \mathrm{P}<0.05$ vs. sh-control ( $\mathrm{n}=3$ ). (E) FBXW7 protein expression was determined by western blotting following FBXW7 overexpression. (F) Western blotting bands were quantified using ImageJ software. Relative FBXW7 expression levels were normalized to $\beta$-actin. ${ }^{*} \mathrm{P}<0.05$ vs. untransfected cells (Blank); ${ }^{\wedge} \mathrm{P}<0.05$ vs. control-OE ( $\mathrm{n}=3$ ). (G) FBXW7 silencing promoted ACHN and SN12PM6 cell proliferation. " $\mathrm{P}<0.05$ vs. untransfected cells; ${ }^{\wedge} \mathrm{P}<0.05$ vs. sh-control $(\mathrm{n}=3)$. FBXW7, F-box and WD repeat domain containing 7 ; RT-qPCR, reverse transcription-quantitative polymerase chain reaction. 

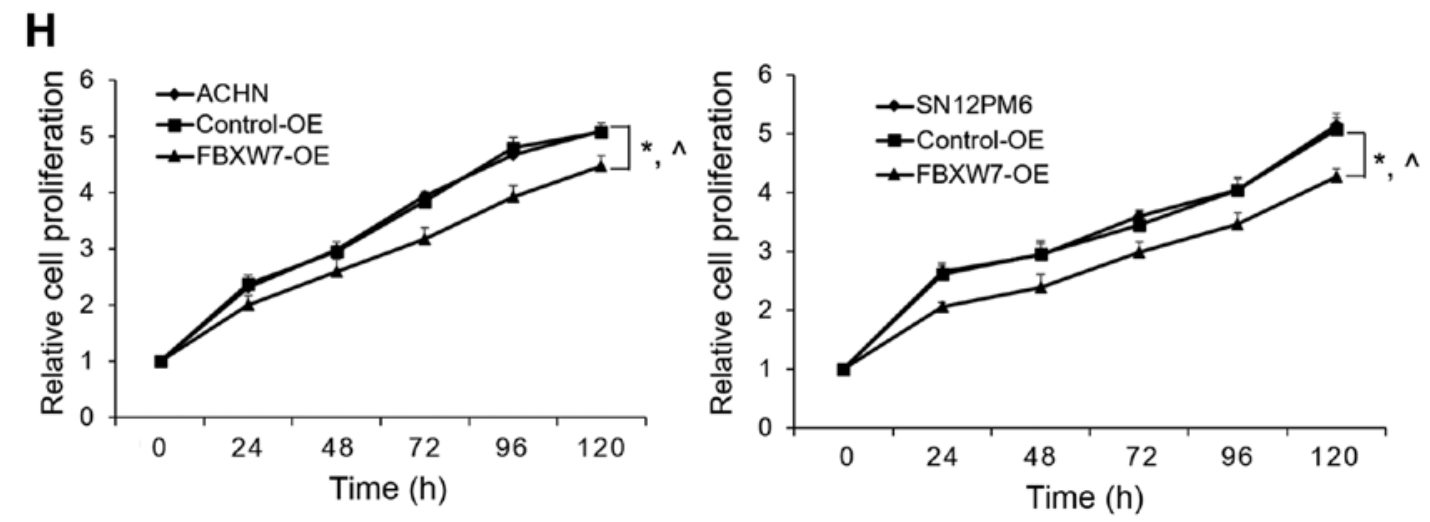

Figure 5. Continued. (H) FBXW7 overexpression inhibited ACHN and SN12PM6 cell proliferation. ${ }^{*} \mathrm{P}<0.05$ vs. untransfected cells; ${ }^{\wedge} \mathrm{P}<0.05$ vs. control-OE $(\mathrm{n}=3)$. FBXW7, F-box and WD repeat domain containing 7; RT-qPCR, reverse transcription-quantitative polymerase chain reaction.

under anchorage-independent conditions compared with untransfected cells (Fig. 2D).

\section{Discussion}

At present, miRNAs dysregulation is an area of great interest when investigating the molecular mechanisms of renal tumorigenesis (30). Numerous studies reported that miRNAs serve crucial roles in the regulation of various cellular processes, including cell cycle control, proliferation, migration and apoptosis $(31,32)$. Furthermore, aberrant miRNA expression has been associated with a wide range of human diseases, including cancer (33-35). Among these miRNAs, miR-92a-3p has been frequently reported to be dysregulated in various types of cancer, including human acute megakaryoblastic leukemia, glioma and Wilms tumor (36-38). For example, miR-92a can mediate AZD6244-induced apoptosis and G1-phase arrest of lymphoma cells by targeting Bim (39). Previous study reported that miR-92a-3p inhibits proliferation, migration and invasion of Wilms tumor cells by targeting notch receptor 1 (NOTCH1) (38). In addition, it has been demonstrated that miR-92a-3p is upregulated in cervical cancer and promotes cell proliferation and invasion by targeting FBXW7 (16). However, the biological function and underlying mechanism of miR-92a-3p in RCC remain unknown. In the present study, miR-92a-3p expression level was significantly increased in RCC tissues compared with paired non-tumorous tissues. Furthermore, miR-92a-3p expression was upregulated in ACHN and SN12PM6 cells compared with HK-2 cells. In addition, miR-92a-3p overexpression promoted RCC cell proliferation and stimulated the number of colonies formed under anchorage-independent conditions. Furthermore, miR-92a-3p downregulation inhibited cell proliferation and reduced colonie number under anchorage-independent conditions. These results suggested that miR-92a-3p may regulate RCC cell proliferation.

The results from the present study suggested that alteration of FBXW7 expression could interfere with the enhancing effects of miR-92a-3p on tumor cell proliferation. In addition, FBXW7 was confirmed to be a direct target of miR-92a-3p in human hepatocellular carcinoma (26). Furthermore, FBXW7 is associated with knockdown of family with sequence similarity 83 member $\mathrm{D}$, and could regulate the proliferation, migration and invasion of colorectal cancer cells (40). In addition, it has been reported that FBXW7 functions as a tumor suppressor, inhibits breast cancer growth and promotes cell apoptosis by targeting metadherin for degradation (41). A previous study reported that melanoma-associated antigen 1 interacts with FBXW7 to regulate the ubiquitin ligase-mediated turnover of Notch1 intracellular domain 1 in breast and ovarian cancer cells (42). FBXW7 upregulation also suppresses metastasis and epithelial mesenchymal transition in RCC (43). However, the biological function and underlying mechanism of FBXW7 on miRNAs remain unknown in RCC. The results from the present study demonstrated that FBXW7 was downregulated in RCC tissues compared with adjacent non-tumorous tissues. Furthermore, miR-92a-3p inversely regulated FBXW7 abundance in RCC cell lines. Besides, miR-92a-3p directly suppressed FBXW7 using a 3'UTR luciferase assay and western blotting. In addition, FBXW7 knockdown significantly promoted cell proliferation and increased the number of colonies formed under anchorage-independent conditions. Conversely, FBXW7 overexpression significantly suppressed cell proliferation and decreased the number of colonies formed under anchorage-independent conditions. These results strongly suggested that FBXW7 may be considered a functional mediator of miR-92a-3p in RCC and that miR-92a-3p may stimulate RCC cell proliferation by regulating FBXW7; however, whether the downstream of FBXW7 is also dysregulated in RCC remains to be investigated.

The results from this study indicated that miR-92a-3p was upregulated in RCC tissues and cells. In addition, miR-92a-3p could be considered as a novel miRNA promoting proliferation and colony formation in RCC cells. The tumor-promoting effect of miR-92a-3p may be associated with FBXW7. In conclusion, the tight regulation of the newly discovered miR-92a-3p/FBXW7 pathway may represent a potential novel strategy and theoretical basis for improving the clinical treatment of RCC.

\section{Acknowledgements}

Not applicable.

\section{Funding}

No funding was received 


\section{Availability of data and materials}

The datasets generated and/or analyzed during the current study are available from the corresponding author on reasonable request.

\section{Author's contributions}

JL and RZ designed the experiments and wrote the manuscript. $\mathrm{RZ}, \mathrm{JH}$ and YS performed the in vitro study and analyzed the data. All the authors read and approve the final version of the manuscript.

\section{Ethics approval and consent to participate}

The present study was approved by the Ethics Committee of Hubei University of Chinese Medicine, and informed consent was obtained from each patient.

\section{Patient consent for publication}

Not applicable.

\section{Competing interests}

The authors declare that they have no competing interests.

\section{References}

1. Kabaria R, Klaassen Z and Terris MK: Renal cell carcinoma: Links and risks. Int J Nephrol Renovasc Dis 9: 45-52, 2016.

2. Capitanio U, Bensalah K, Bex A, Boorjian SA, Bray F, Coleman J, Gore JL, Sun M, Wood C and Russo P: Epidemiology of renal cell carcinoma. Eur Urol 75: 74-84, 2019.

3. Hsieh JJ, Purdue MP, Signoretti S, Swanton C, Albiges L, Schmidinger M, Heng DY, Larkin J and Ficarra V: Renal cell carcinoma. Nat Rev Dis Primers 3: 17009, 2017.

4. Zhou J, Yun EJ, Chen W, Ding Y, Wu K, Wang B, Ding C, Hernandez E, Santoyo J, Pong RC, et al: Targeting 3-phosphoinositide-dependent protein kinase 1 associated with drug-resistant renal cell carcinoma using new oridonin analogs. Cell Death Dis 8: e2701, 2017.

5. Campbell SC, Flanigan RC and Clark JI: Nephrectomy in metastatic renal cell carcinoma. Curr Treat Options Oncol 4: 363-372, 2003.

6. Doberstein K, Steinmeyer N, Hartmetz AK, Eberhardt W, Mittelbronn M, Harter PN, Juengel E, Blaheta R, Pfeilschifter J and Gutwein P: MicroRNA-145 targets the metalloprotease ADAM17 and is suppressed in renal cell carcinoma patients. Neoplasia 15: 218-230, 2013.

7. Conti A, Santoni M, Amantini C, Burattini L, Berardi R, Santoni G, Cascinu S and Muzzonigro G: Progress of molecular targeted therapies for advanced renal cell carcinoma. Biomed Res Int 2013: 419176, 2013.

8. Guo H, Ingolia NT, Weissman JS and Bartel DP: Mammalian microRNAs predominantly act to decrease target mRNA levels. Nature 466: 835-840, 2010.

9. Bhat NS, Colden M, Dar AA, Saini S, Arora P, Shahryari V, Yamamura S, Tanaka Y, Kato T, Majid S and Dahiya R: MicroRNA-720 regulates E-cadherin- $\alpha$ E-catenin complex and promotes renal cell carcinoma. Mol Cancer Ther 16: 2840-2848, 2017.

10. Ying G, Wu R, Xia M, Fei X, He QE, Zha C and Wu F: Identification of eight key miRNAs associated with renal cell carcinoma: A meta-analysis. Oncol Lett 16: 5847-5855, 2018.

11. Chen ZL, Zhao XH, Wang JW, Li BZ, Wang Z, Sun J, Tan FW, Ding DP, Xu XH, Zhou F, et al: microRNA-92a promotes lymph node metastasis of human esophageal squamous cell carcinoma via E-cadherin. J Biol Chem 286: 10725-10734, 2011.
12. Nilsson S, Möller C, Jirström K, Lee A, Busch S, Lamb R and Landberg G: Downregulation of miR-92a is associated with aggressive breast cancer features and increased tumour macrophage infiltration. PLoS One 7: e36051, 2012.

13. Ohyagi-Hara C, Sawada K, Kamiura S, Tomita Y, Isobe A, Hashimoto K, Kinose Y, Mabuchi S, Hisamatsu T, Takahashi T, et al: miR-92a inhibits peritoneal dissemination of ovarian cancer cells by inhibiting integrin alpha5 expression. Am J Pathol 182: 1876-1889, 2013.

14. Ranade AR, Cherba D, Sridhar S, Richardson P, Webb C, Paripati A, Bowles B and Weiss GJ: MicroRNA 92a-2*: A biomarker predictive for chemoresistance and prognostic for survival in patients with small cell lung cancer. J Thorac Oncol 5: 1273-1278, 2010.

15. $\mathrm{Wu} \mathrm{CW}$, Ng SS, Dong YJ, Ng SC, Leung WW, Lee CW, Wong YN, Chan FK, Yu J and Sung JJ: Detection of miR-92a and miR-21 in stool samples as potential screening biomarkers for colorectal cancer and polyps. Gut 61: 739-745, 2012.

16. Zhou C, Shen L, Mao L, Wang B, Li Y and Yu H: miR-92a is upregulated in cervical cancer and promotes cell proliferation and invasion by targeting FBXW7. Biochem Biophys Res Commun 458: 63-69, 2015.

17. Yeh $\mathrm{CH}$, Bellon $\mathrm{M}$ and Nicot $\mathrm{C}$ : FBXW7: A critical tumor suppressor of human cancers. Mol Cancer 17: 115, 2018.

18. Inuzuka H, Shaik S, Onoyama I, Gao D, Tseng A, Maser RS, Zhai B, Wan L, Gutierrez A, Lau AW, et al: SCF(FBW7) regulates cellular apoptosis by targeting MCL1 for ubiquitylation and destruction. Nature 471: 104-109, 2011.

19. Wertz IE, Kusam S, Lam C, Okamoto T, Sandoval W, Anderson DJ, Helgason E, Ernst JA, Eby M, Liu J, et al: Sensitivity to antitubulin chemotherapeutics is regulated by MCL1 and FBW7. Nature 471: 110-114, 2011.

20. Chang H, Liu YH, Wang LL, Wang J, Zhao ZH, Qu JF and Wang SF: MiR-182 promotes cell proliferation by suppressing FBXW7 and FBXW11 in non-small cell lung cancer. Am J Transl Res 10: 1131-1142, 2018.

21. Hua J, Ding T and Yang L: Dysfunction of microRNA-32 regulates ubiquitin ligase FBXW7 in multiple myeloma disease. Onco Targets Ther 9: 6573-6579, 2016.

22. Kim SP, Alt AL, Weight CJ, Costello BA, Cheville JC, Lohse C, Allmer C and Leibovich BC: Independent validation of the 2010 American joint committee on cancer TNM classification for renal cell carcinoma: Results from a large, single institution cohort. J Urol 185: 2035-2039, 2011.

23. Livak KJ and Schmittgen TD: Analysis of relative gene expression data using real-time quantitative PCR and the 2(-Delta Delta C(T)) method. Methods 25: 402-408, 2001.

24. Xiao Y, Yin C, Wang Y, Lv H, Wang W, Huang Y, Perez-Losada J, Snijders AM, Mao JH and Zhang P: FBXW7 deletion contributes to lung tumor development and confers resistance to gefitinib therapy. Mol Oncol 12: 883-895, 2018.

25. Xu Y, Sengupta T, Kukreja L and Minella AC: MicroRNA-223 regulates cyclin $\mathrm{E}$ activity by modulating expression of F-box and WD-40 domain protein 7. J Biol Chem 285: 34439-34446, 2010.

26. Yang W, Dou C, Wang Y, Jia Y, Li C, Zheng X and Tu K: MicroRNA-92a contributes to tumor growth of human hepatocellular carcinoma by targeting FBXW7. Oncol Rep 34: 2576-2584, 2015.

27. Liu Z, Tu K and Liu Q: Effects of microRNA-30a on migration, invasion and prognosis of hepatocellular carcinoma. FEBS Lett 588: 3089-3097, 2014.

28. Qiu M, Xu Y, Wang J, Zhang E, Sun M, Zheng Y, Li M, Xia W, Feng D, Yin R and Xu L: A novel lncRNA, LUADT1, promotes lung adenocarcinoma proliferation via the epigenetic suppression of p27. Cell Death Dis 6: e1858, 2015.

29. Borowicz S, Van Scoyk M, Avasarala S, Karuppusamy Rathinam MK, Tauler J, Bikkavilli RK and Winn RA: The soft agar colony formation assay. J Vis Exp e51998: 2014.

30. Calin GA and Croce CM: MicroRNA signatures in human cancers. Nat Rev Cancer 6: 857-866, 2006.

31. Liu Z, Sun J, Liu B, Zhao M, Xing E and Dang C: miRNA222 promotes liver cancer cell proliferation, migration and invasion and inhibits apoptosis by targeting BBC3. Int J Mol Med 42: 141-148, 2018.

32. Pan BL, Wu L, Pan L, Yang YX, Li HH, Dai YJ, He ZQ, Tan L, Huang YG, Tong ZW and Liao JL: Up-regulation of microRNA-340 promotes osteosarcoma cell apoptosis while suppressing proliferation, migration, and invasion by inactivating the CTNNB1-mediated Notch signaling pathway. Biosci Rep 38: BSR20171615, 2018. 
33. Jafri MA, Al-Qahtani MH and Shay JW: Role of miRNAs in human cancer metastasis: Implications for therapeutic intervention. Semin Cancer Biol 44: 117-131, 2017.

34. Oliveto S, Mancino M, Manfrini $\mathrm{N}$ and Biffo S: Role of microRNAs in translation regulation and cancer. World J Biol Chem 8: 45-56, 2017.

35. Venkatadri R, Muni T, Iyer AK, Yakisich JS and Azad N: Role of apoptosis-related miRNAs in resveratrol-induced breast cancer cell death. Cell Death Dis 7: e2104, 2016.

36. Sharifi M and Salehi R: Blockage of miR-92a-3p with locked nucleic acid induces apoptosis and prevents cell proliferation in human acute megakaryoblastic leukemia. Cancer Gene Ther 23: 29-35, 2016.

37. Wang Q, Teng Y, Wang R, Deng D, You Y, Peng Y, Shao N and Zhi F: The long non-coding RNA SNHG14 inhibits cell proliferation and invasion and promotes apoptosis by sponging miR-92a-3p in glioma. Oncotarget 9: 12112-12124, 2018.

38. Zhu S, Zhang L, Zhao Z, Fu W, Fu K, Liu G and Jia W: MicroRNA92a3p inhibits the cell proliferation, migration and invasion of Wilms tumor by targeting NOTCH1. Oncol Rep 40: 571-578, 2018.

39. Lv XB, Zhang X, Deng L, Jiang L, Meng W, Lu Z and Wang X: MiR-92a mediates AZD6244 induced apoptosis and G1-phase arrest of lymphoma cells by targeting Bim. Cell Biol Int 38: $435-443,2014$
40. Mu Y, Zou H, Chen B, Fan Y and Luo S: FAM83D knockdown regulates proliferation, migration and invasion of colorectal cancer through inhibiting FBXW7/Notch-1 signalling pathway. Biomed Pharmacother 90: 548-554, 2017.

41. Chen X, Li XY, Long M, Wang X, Gao ZW, Cui Y, Ren J, Zhang Z, Liu C, Dong K and Zhang H: The FBXW7 tumor suppressor inhibits breast cancer proliferation and promotes apoptosis by targeting MTDH for degradation. Neoplasma 65: 201-209, 2018

42. Zhao J, Wang Y, Mu C, Xu Y and Sang J: MAGEA1 interacts with FBXW7 and regulates ubiquitin ligase-mediated turnover of NICD1 in breast and ovarian cancer cells. Oncogene 36: 5023-5034, 2017

43. Cai Y, Zhang M, Qiu X, Wang B, Fu Y, Zeng J, Bai J and Yang G: Upregulation of FBXW7 suppresses renal cancer metastasis and epithelial mesenchymal transition. Dis Markers 2017: 8276939, 2017.

This work is licensed under a Creative Commons Attribution-NonCommercial-NoDerivatives 4.0 International (CC BY-NC-ND 4.0) License. 